\title{
Defect Formation and Material Flow in Friction Stir Welding
}

\author{
Narges Dialami *, Miguel Cervera and Michele Chiumenti \\ International Center for Numerical Methods in Engineering (CIMNE), \\ Universidad Politécnica de Cataluña, \\ Campus Norte UPC, 08034 Barcelona, Spain; \\ * Correspondence: Narges@cimne.upc.edu; Tel.: +34 934016529 \\ Miguel.Cervera@upc.edu; Michele@cimne.upc.edu
}

\begin{abstract}
This work addresses the issue of the simulation and prediction of defect formation through the analysis of the material mixing during Friction Stir Welding (FSW). A coupled thermomechanical model is used for the FSW simulation. To follow the flow of the material, a tracing technique of the material particles is incorporated in the numerical model.

A fast and accurate two-stage numerical strategy is adopted to analyse the FSW process. The speed-up stage intends to reach the steady state quickly. The material tracing is performed in the periodic stage where the rotation of the tool is modelled.

The effect of the process parameters and the pin features on the defect formation is studied. The model is capable of predicting defects such as void, wormhole, flash and joint line remnant, as well as the formation of "onion rings" in a single simulation. The results show that the proposed model has significant capability to explain and predict the post-FSW defects.
\end{abstract}

Keywords: FSW, Material flow, Defect formation, Computational modelling.

\section{INTRODUCTION}

Friction Stir Welding (FSW) is a solid state welding technology that has been widely used, due to the low defect and the lack of melting, in shipbuilding, trains, and aerospace industries since its invention [1]. Being a solid state joining technique, FSW precludes defects such as hot cracking and porosity. It is applied to join different types of alloys such as aluminium, stainless steel and magnesium which are hard to be welded using the traditional welding techniques.

FSW is a coupled thermomechanical process where the weld properties and the microstructure are affected by the heat and mass transfer [2]. Heat is generated by friction and plastic deformation. Higher heat input improves the material flow and mixing. High quality FSW joints are achieved by an appropriate material flow. As the microstructure evolution and mechanical properties of FSWeld alloys depend on the material flow in the joints.

The extent of the mass transfer and consequently, the joint quality made by FSW can be affected by many factors. Among them, the welding parameters such as advancing and rotating speeds [3, 4] and the tool shape [5-7] have a great influence on the material flow during FSW. Insufficient material flow during the welding process is the origin of the 
defect formation such as wormhole, tunnel defect, voids and joint line remnant [8]. These defects preclude the achievement of high strength joints as they influence the formation of the weld and affect the microstructure and hence the corresponding mechanical properties [9]. The cause of defect formation in FSW is one of the topics that requires further investigation.

Several types of defects may emerge due to an inappropriate combination of rotating and advancing velocities [10]. Unsuitable choice of these velocities may cause insufficient or excessive heat input or abnormal stirring [11]. Wormholes and tunnel defects generally appear in the advancing side and are due to poor heat input and material flow [12]. Kissing bond and joint line remnant defects occur at low rotating and high advancing speeds [13]. As a result of incomplete stirring action and poor heat input, the oxide layer breaks, reduces the flow of the plasticized material and forms the joint line remnant defect. High advancing speed induces void formation on the advancing side at the edge of the weld nugget [14].

Material flow in FSW has been extensively studied experimentally to analyse the mechanisms of defect formation. Reynolds [15] used a marker material method to characterize the material flow in aluminium alloy 2195 and to describe the physical behaviour of FSW using a qualitative representation of the material flow.

Hou et al. [16] studied the influence of different T-joint geometries on the formation mechanism of the defects in FSW. Kissing bond and tunnel defect were found in all their tests. They observed that by reducing the advancing speed these defects are significantly alleviated due to the higher heat input and improvement of the material flow.

Khan et al. [17] studied the effect of the tool offset and tool plunge depth on the formation of kissing bond and tunnel defect during the welding of AA5083-H116 and AA6063-T6. They observed that these imperfections can be overwhelmed by keeping an appropriate offset during the FSW of dissimilar alloys.

Zhao et al. [18] investigated the process of defect formation in FSW of 6013-T4 T-joints. They observed that the process parameters change the sizes of the kissing bond defect and, moreover, that increasing the advancing speed augments the tunnel defect area.

Pandya et al. [19] studied experimentally the material flow during FSW and its association to the channel formation in Friction Stir Channelling (FSC) processes. FSC depends on the idea of changing the void or tunnel defect commencing in the advancing side of FSW into a ceaseless channel. They found out different pin and shoulder influenced material regions causing the channel formation.

Zeng et al. [20] used oxide layer as marker material in order to study the material flow and defect formation in FSW. They concluded that the reason for the void formation on the advancing side is the spontaneous void formation and the deficient inflow material. It was also demonstrated experimentally that the threaded tool pin may preclude imperfections which are likely to occur for an unthreaded tool pin [21-23].

Experimental characterization of FSWelds is difficult and expensive, and the existing techniques are incapable of providing profound insight into the underlying mechanisms. Detection of the defects is only possible using macrographic tools [24, 25].

In this situation, numerical modelling is an alternative or complementary means to reveal the joining mechanism behind the FSW process and to detect possibility of defect formation. Moreover, it can be applied to all the range of material alloys [26]. Such computational procedures have also been used in numerous recent studies.

Zhao et al. [27] examined the connection between revolution speed, plasticized area, and defect development. Examination of the results of a 3D CFD simulation demonstrated that the development of tunnelling defects at lower rotating speeds is related to an expansive variety in the span of the plasticized area over the workpiece thickness. 
Al-Badour et al. [28] developed a numerical model to predict the conditions leading to defect generation in FSW using a cylindrical tool pin. They used a coupled Lagrangian Eulerian formulation where the workpiece is Eulerian and the tool is Lagrangian. The estimated equivalent plastic strain was used as an indicator to visualize the voids. They observed that the friction coefficient has a major influence on the void formation: the lower is the friction coefficient, the larger is the void size. A similar approach was used by Zhu et al. [29] and similar results were observed. Moreover, they concluded that a featured tool pin can improve the material flow resulting in a defect free weld. Both studies overestimated the void size.

Fraser et al. [30] used a mesh-free Lagrangian SPH method to simulate the FSW process. Their model could predict free surface changes and flash formation.

Atharifar et al. [31] carried out a study using a coupled thermo-flow model to find out the origin of tunnel defect in FSW of AA6061-T6. They predicted the down-stream stagnation point in the area where the tunnel defect is originated.

Zhu et al. [32] studied the material flow behaviour during FSW of AA2024-T4 using a CFD model. By using tracing particles, they predicted wormhole defects overestimated in size. They concluded that an inadequate friction force on the bottom trailing side of the pin is the fundamental origin of wormhole defects.

Tutunchilar et al. [33] used a Lagrangian model to study the material flow in FSW. They predicted the stir zone shape and tunnel defect at the advancing side behind the pin.

In contrast to the previous works concentrated on particular defect types, in this paper, we strive to develop a framework capable of predicting formation of a wide range of defects such as wormhole, flash, void and joint line remnant [34]. Moreover, the model can predict the formation of the "onion rings" pattern which has not been numerically investigated so far.

To this end, a single FSW simulation, is equipped with material particle tracing technique to track the flow of the material during the entire FSW process [35, 36].

A coupled thermo-mechanical model is adopted where the domain of the problem is divided into three subdomains corresponding to tool, stir zone and the rest of the plate [37]. An apropos kinematic framework is adopted capable of mixing different kinematic settings associated to each of the sub domains: Lagrangian for the tool, Arbitrary Lagrangian Eulerian (ALE) for the stir zone and Eulerian for the rest of the plate.

To accelerate the simulation time, a fast and accurate two-stage strategy is adopted aiming to reach the steady state rapidly and use it as a starting point for the periodic stage simulation [38]. The material tracing is performed at the post processing phase of each time step.

The present FSW model considers heat generated by both plastic dissipation and friction between the tool and the workpiece. The enhanced friction model incorporated [39, 40] provides not only the realistic thermal results but also mechanical results in terms of forces and torque. The effect of tool tilt angle can also be considered by the modification of this friction model [41]. A rotating angle is included into the friction shear stress distribution depending on the welding parameters such as tilt angle, rotating and advancing speeds. The FSW model is also capable of predicting the average grain size and microhardness [42].

The paper is outlined as follows. In section 2, the causes for defect formation in FSW are briefly described. In section 3, the methodology used to model FSW process and track the flow of the material is introduced. In section 4, two pin profiles and various welding parameters are employed to study the effect of each one of them on the final defect formation. The paper concludes with some summarizing remarks. 


\section{DEFECT FORMATION IN FSW}

During FSW process several types of defects may occur due to the inappropriate definition of the process parameters. Common FSW defects include flash, voids, wormholes and joint line remnant. Depending on the FSW conditions the reasons for defect formation are the following:

- Extreme heat input

- Insufficient heat input

- Abnormal stirring

According to Kim et al. [3], defects are formed outside the optimal FSW processing window depending on the advancing and rotating speeds (figure 1).

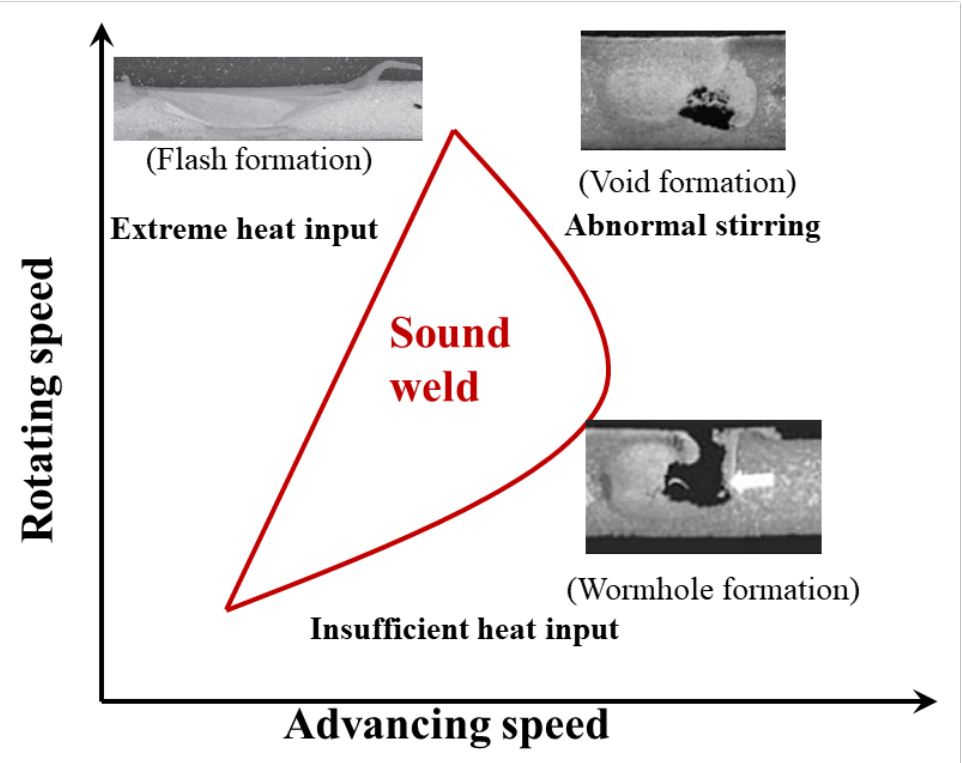

Figure 1. FSW process window and corresponding weld defects

Flash defects, formed by excessive heat input (left side of the optimum zone of FSW process parameters), typically appear when the rotating speed is considerably higher than the advancing one. The workpiece goes under hot processing conditions and severe plastic deformation. The excessive heat generated softens the material close to the tool and expulses the material in the form of flash as a result of high tool shoulder pressure.

Void defects, formed by insufficient heat input (right-bottom side of the optimum zone of FSW process parameters), generally appear when the advancing speed is considerably higher than the rotating one. Even though a high advancing speed assists in an economical and productive FSW process, it may lead to void formation on the advancing side at the border of the weld nugget. Further increase of the advancing speed leads to the formation of wormhole defects due to insufficient plastic flow and lack of filling.

Void and cavity type defects, formed by abnormal stirring (right-top side of the optimum zone of FSW process parameters), appear at high rotating speed and high advancing speeds. They are due to the temperature difference between the top surface and the bottom part, causing discontinuous flow of the material. High rotating speed provokes high temperature with gradual cooling rate in the stir zone; additionally, high advancing speed 
leads to disproportionate release of the stirred material to the upper surface both resulting in void generation.

The joint line remnant defect appears when the advancing speed is high and the rotating speed is low. The oxide layer at the welding interface of the original workpiece fractionally breaks in a zigzag form as the heat input and the stirring action is insufficient to let the material flow properly.

\section{METHODOLOGY}

\subsection{FSW MODEL AND PARTS}

In this work, the simulation of the FSW process is performed by taking into account the specific features of the process at the different parts involved in the weld. Three parts are considered: tool, stir zone and the workpiece (figure 2). The stir zone is considered to be a cylindrical zone surrounding the tool. The tool rotates with a constant velocity around its fixed axis. The advancing movement of the tool is modelled by the movement of the workpiece with the advancing velocity in the opposite direction.

An apropos kinematic framework is adopted combining Lagrangian, Arbitrary Lagragian Eulerian (ALE) and Eulerian settings [37]. The rigidly rotating tool is modelled in a Lagrangian setting. The stir zone, where major material deformation occurs, is modelled in a ALE framework. The flow of the material in this zone is mainly rotational, due to the high speed rotation of the tool. The rest of the workpiece is modelled in an Eulerian framework. The flow of the material in this region is predominantly horizontal due to the advancing velocity.

Regarding finite element analysis, in the Lagrangian framework, material moves together with its mesh, in the Eulerian framework, the mesh is fixed, and in the ALE framework, the material on the mesh move independently. As the flow in the region modelled by ALE is predominantly rotational, the mesh velocity is set equal to the tool rotating velocity. This facilitates the coupling between the ALE and Lagrangian parts. The coupling between the ALE and Eulerian parts is achieved via defining structured matching meshes at the interface. The time step is defined such that at each time a node to node synchronization of the ALE and Eulerian meshes is assured.
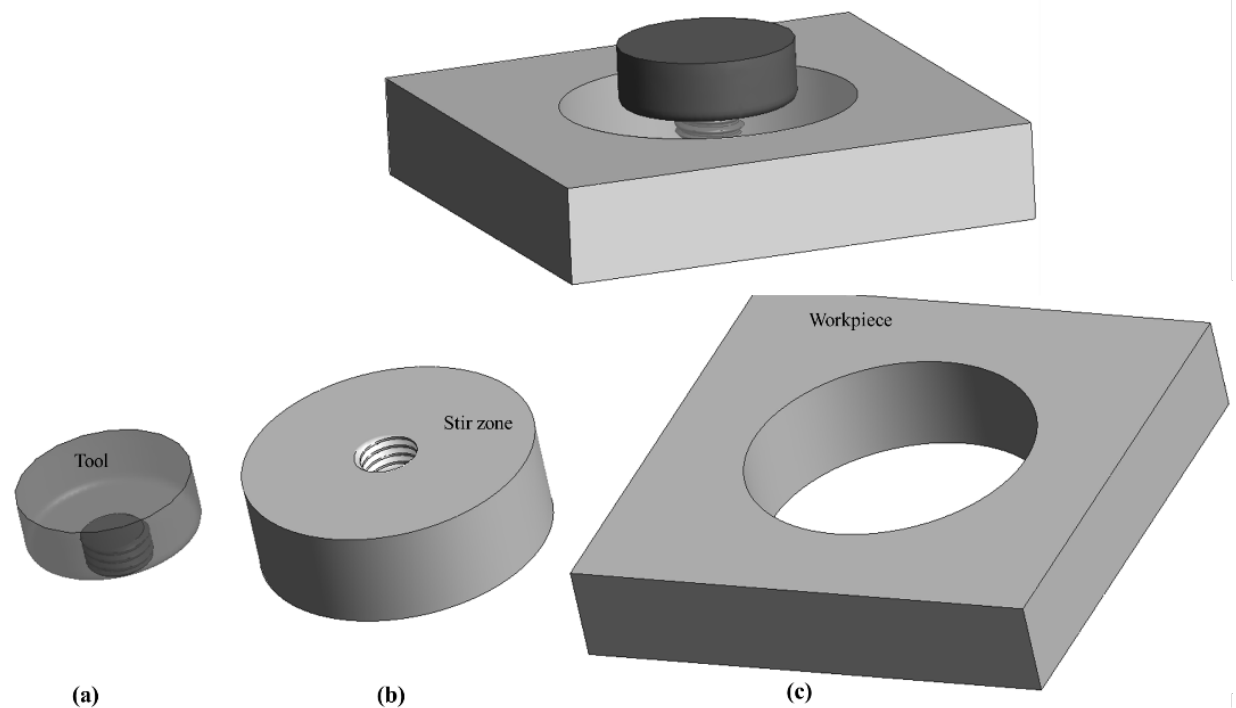

Figure 2. FSW model and sub-parts: (a) Lagrangian tool (b) ALE stir zone (c) Eulerian workpiece 
The present FSW model includes an enhanced friction model where the effect of the nonuniform pressure distribution under the tool at contact with the stir zone is taken into account $[39,40]$. The friction model is a modified Norton's law.

$$
\boldsymbol{\tau}_{T}=\tau\left\|\Delta \mathbf{v}_{T}\right\|^{q-1} \Delta \mathbf{v}_{T},
$$

where $\boldsymbol{\tau}_{T}$ is the friction shear stress, $\Delta \mathbf{v}_{T}$ is the relative velocity between tool and workpiece, $q$ is the sensitivity coefficient. The friction traction parameter $\tau$ accounts for the dependence of the pressure on the position with regard to the advancing velocity:

$$
\tau=0.5\left(\tau_{\max }+\tau_{\min }+\left(\tau_{\max }-\tau_{\text {min }}\right) \tanh \frac{x}{R / 6}\right)
$$

$x$ being the horizontal (weld line direction) distance of each point on the contact surface from the axis of rotation and $R$ is the radius of the tool shoulder; $\tau_{\max }$ and $\tau_{\min }$ are the maximum and the minimum friction traction parameters, respectively. The friction value is maximum at front side of the tool decreasing to a minimum at the rear of the tool (figure 3).

In this work, the heat is generated from the friction law and the plastic deformation of the material close to the tool. Details on the enhanced friction law and the thermomechanical model developed by the authors are given in [37, 39].
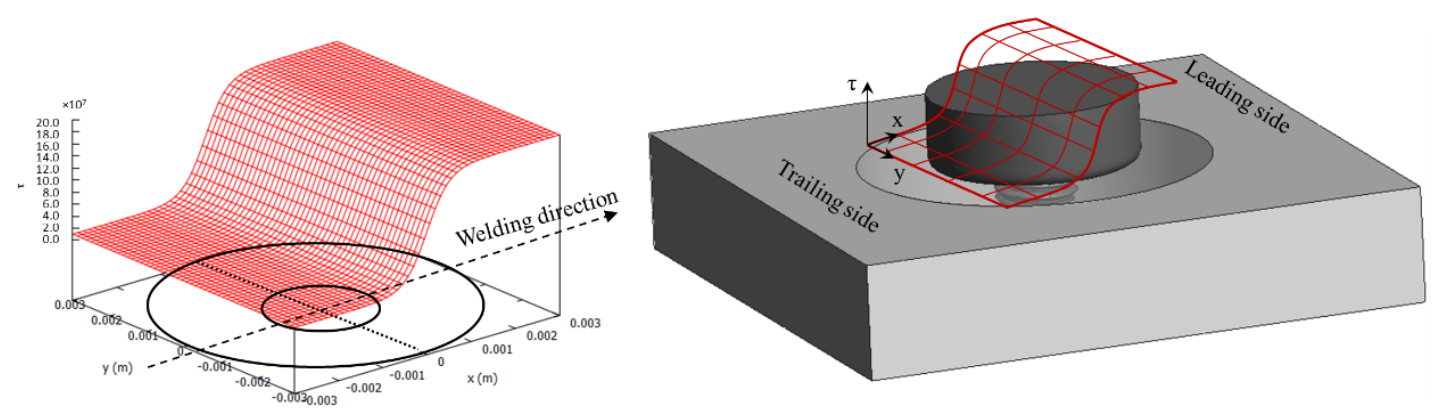

Figure 3. Friction traction distribution at tool workpiece interface (without tilt angle)

\subsection{TWO-STAGE STRATEGY}

The FSW model includes a fast and accurate two-stage strategy for the simulation of the entire process [38] (figure 4). At both stages, coupled thermomechanical behaviour is considered where the thermal and mechanical problems are solved sequentially at each step. The mechanical problem is quasi-static as FSW is characterized by very low values of the Reynolds number, typically around $10^{-4}$, due to the very high viscosity of the material. For these values of the Reynolds number, inertial effects are negligible. Contrariwise, the thermal problem is transient. The featured pin-workpiece contact interface is constantly changing with time; thus performing a transient simulation is essential.

At the first stage, the speed-up phase of the simulation is performed. The aim of this phase is to reach the steady state solution by accelerating the inertia term of the energy balance equation. At this stage, the coupled thermomechanical problem is solved at a fixed configuration inside a fully Eulerian kinematic setting. In the case of a pin with features 
the fixed configuration can be any of the configurations adopted by the rotating pin. The speed up strategy is designed to accelerate the thermal partition of the first stage. Being the mechanical properties very strongly temperature dependent, the main objective of the first stage is to get a proper temperature field so that the corresponding mechanical properties can be estimated. The speed-up stage reduces the simulation time by the factor of 50 if compared to the standard transient models, permitting to start from the transient state approaching to the steady state. In the first stage of the simulation, no periodic phase exists but a steady state is achieved by the speed up procedure.

At the second stage, the periodic phase of the simulation is performed. This stage allows for modelling the problem considering the real periodic movement of the tool from the initial condition that is the result of the first stage. The periodic stage is necessary in order to model and track the material flow due to this movement. At this stage the coupled thermomechanical problem is defined in a rotating configuration within the apropos kinematic framework (combined Lagrangian, ALE and Eulerian). The FSW analysis at second stage leads to a steady state periodic solution.

This strategy allows a significant reduction of the simulation time while allowing the modelling of asymmetrical pin and material flow visualization.

Due to the asymmetry of the pin shape in case of threaded profile the solution for every rotation of the pin at the second stage is periodical.

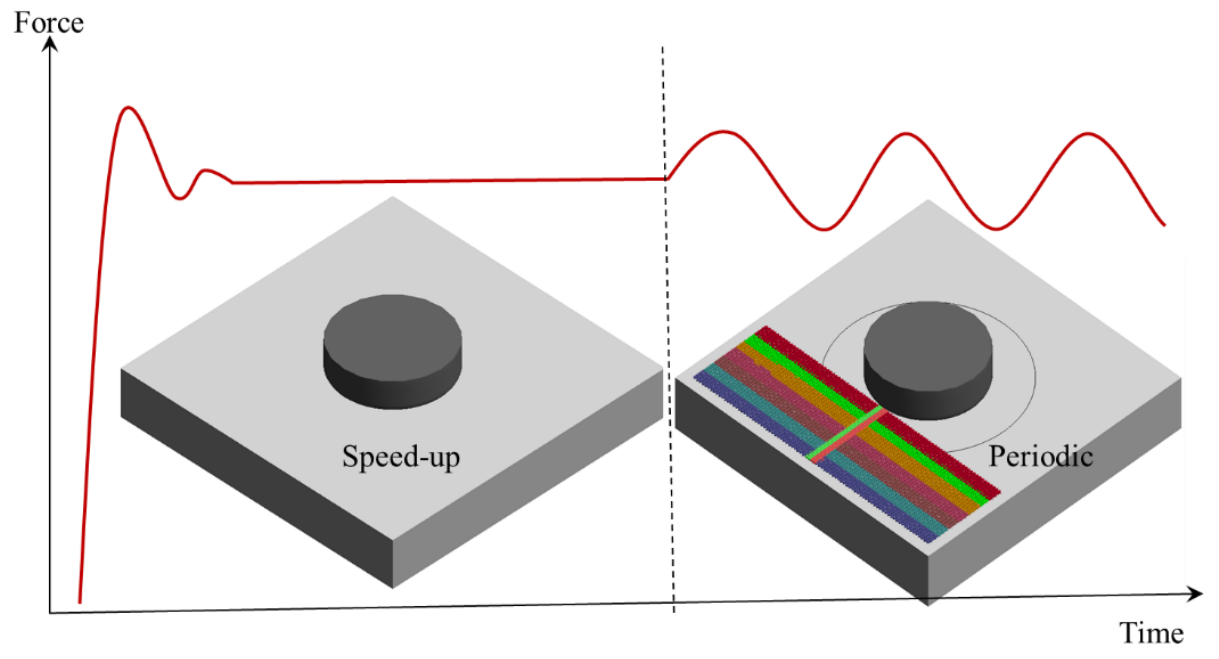

Figure 4. Two-stage (speed-up and periodic) strategy

\subsection{MATERIAL PARTICLE TRACING}

The FSW model developed for the analysis of the process at local level (a domain that includes the thermo-mechanically affected zone) is a flow model. The deviatoric stresses are function of the strain rate rather than the strains. In the flow problem the use of Eulerian/ALE framework is a natural choice. However, in these frameworks material deformation is not tracked directly. In the numerical models where an ALE framework is used the movement of the mesh does not coincide with the material movement. In the Eulerian framework the mesh is fixed. In the ALE framework the mesh is moving with a velocity different from the material velocity. In such frameworks, an additional strategy is needed to follow the material [35, 36]. The formulation of the FSW model is based on FEM and continuum mechanics. In an ALE/Eulerian configuration no information about the defects such as void and stresses can be obtained. 
In this work, a material tracing technique is incorporated to visualize the material flow during FSW. However, the tracers represent the material particles. The objective is, to follow the movement of a set of material particles positioned initially in front of the tool. The location of each particle is detected by using a search algorithm. The velocity of the particles is found from the nodal velocities of the element surrounding them at each step of the FSW simulation (figure 5). The material tracers coming into the stirring zone move forward and rotate around the tool according to the computed velocity field.

The material tracers are incorporated in a Lagrangian framework. To obtain the position of a particle in time, $\mathbf{X}(t)=\mathbf{X}$, the following ordinary differential equation needs to be solved:

$$
\frac{D \mathbf{X}}{D t}=\mathbf{V}(\mathbf{X}, t)
$$

where $\mathbf{V}(\mathbf{X}, t)$ is the material particle velocity at its current position. A $4^{\text {th }}$ order RungeKutta integration method is used to obtain the position of the particles, $\mathbf{X}\left(t_{n+1}\right)=\mathbf{X}_{n+1}$ from the current position $\mathbf{X}\left(t_{n}\right)=\mathbf{X}_{n}$ (figure 6).

More details on the material tracing technique are given in [35, 36].

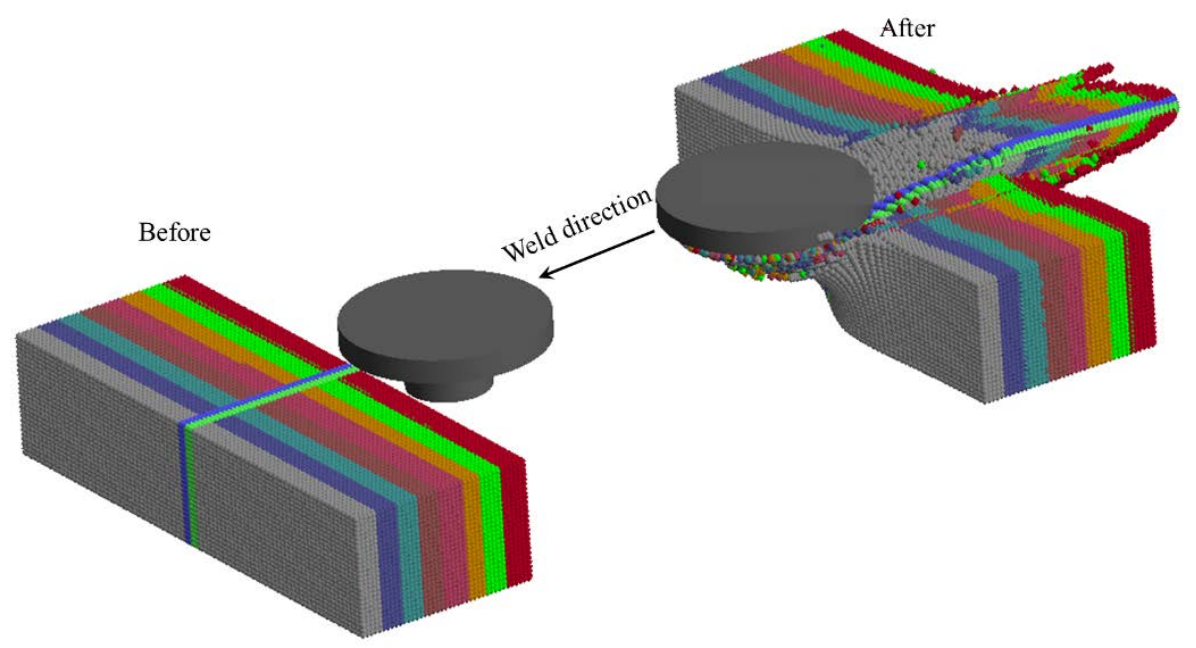

Figure 5. Material particles before and after FSW 


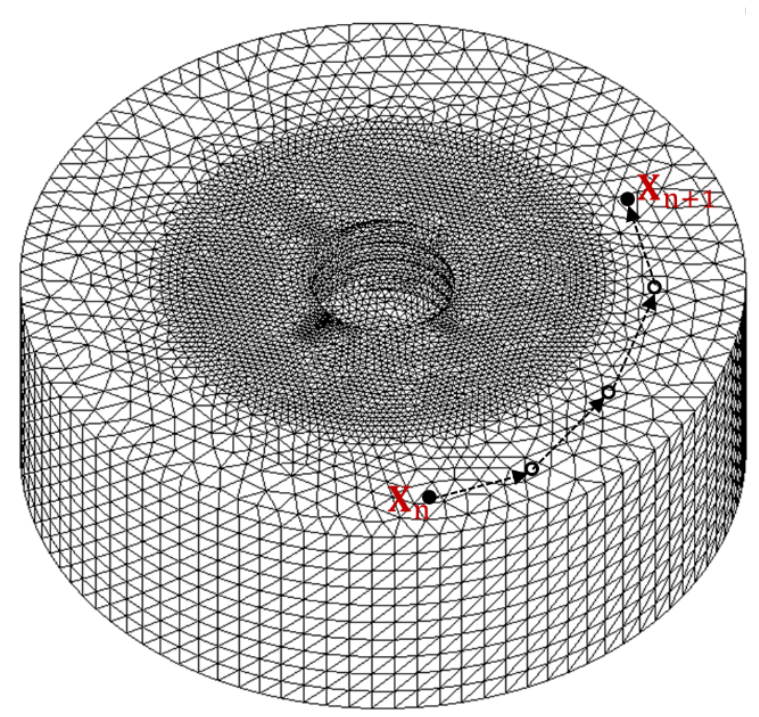

Figure 6. Material tracking steps

\section{MATERIAL FLOW AND DEFECT FORMATION}

In the following, two different tool profiles, cylindrical featureless and cylindrical threaded, are considered. For each of them, several FSW processes are studied in terms of the material flow to detect different defects, and to investigate how defect formation is affected by the tool pin profile and the welding parameters.

The FSW model adopted here is calibrated for both tool profiles via experimental evidence in terms of temperature, torque and forces obtained under equivalent processing conditions [39, 40].

The numerical simulations shown in this work, using the two-stage procedure, run to completion in terms of 8-10 hours of elapsed time for each case analysed in an intel quadcore i7 computer.

\subsection{FEATURELESS CYLINDRICAL PIN}

In this section the analysis of FSW processes using a featureless cylindrical pin is performed in order to investigate the effect of welding parameters in defect formation.

A flat shouldered tool with a diameter of $18 \mathrm{~mm}$ and a featureless pin of $7 \mathrm{~mm}$ diameter are considered. The height of the pin is $4 \mathrm{~mm}$. Tilt angle is zero. The aluminium alloy (Al6063-T6) is the material considered.

Three cases of tool advancing and rotating speeds (clockwise) are examined; (a) 400 $\mathrm{mm} / \mathrm{minute}$ and $600 \mathrm{rpm}$; (b) $400 \mathrm{~mm} / \mathrm{minute}$ and $300 \mathrm{rpm}$; (c) $200 \mathrm{~mm} / \mathrm{minute}$ and 600 rpm.

The thermomechanical results obtained for case (a) were validated against experimental results and presented in [39].

In order to track the material flow, a set of 300,000 material tracers is distributed uniformly in front of the tool in a domain of $46 \times 16 \times 10 \mathrm{~mm}^{3}$. The initial position of the tracers is shown in figure 7 with respect to the welding direction (negative $\mathrm{X}$-axis). Different colours in transversal and horizontal directions are chosen to achieve a better resolution in depicting the material flow together with the detail of the defects. Moreover, the evenly distributed tracers of different colours allow for visualizing the band structures formed after the weld. 
The material tracers follow the advancing and rotating movement of the tool. As noted previously, the advancing movement is applied to the workpiece in the direction opposite to the weld direction and the tool rotates with the rotating speed. Once all the material tracers have passed through the tool, the final position of the tracers is recorded (figure 8 in case (a)). This final position means that the vertical and transversal coordinates of the tracers do not change afterwards, but they only move along the advancing direction. An observation plane is selected in the middle of the tracers by performing a transversal cut (line ab) through the tracers volume. The same procedure is applied for all the cases described later on.

The obtained material pattern for all the three cases is shown in figure 9. Defect formation can also be observed.

Case (a) presents small defects due to the abnormal stirring produced by the high rotating and advancing speeds. These conditions, according to figure 1 defined by [3], are located at the right-top zone of the optimum FSW process parameters. The reason for this defect is found to be the large temperature difference between the top and the bottom surfaces, which contributes to the abnormal stirring and hence discontinuous material flow in the weld area. In case (b), a sound quality joint is formed. In case (c), the defects are formed because of excessive heat input. These defects commonly appear when the rotating speed is considerably higher than the advancing one. According to figure 1 , the defects are located at the left-top zone of the optimum FSW process parameters. This type of defects consists of a series of visible voids located on the advancing side. Due to the disproportionate heat generation, an excessive softening of the material behind the boundary of the tool shoulder occurs. Therefore, the tool shoulder expulses the material instead of enclosing it. Consequently, lack of material at the weld area contributes to a defective weld.

In order to see the effect of the process parameters on the type of defects generated in cases (a) and (c), three additional cases are studied: (d) $400 \mathrm{~mm} /$ minute and $1200 \mathrm{rpm}$; (e) $600 \mathrm{~mm} /$ minute and $600 \mathrm{rpm}$; (f) $600 \mathrm{~mm} /$ minute and $200 \mathrm{rpm}$.

In case (d), very high rotating speed comparing to the advancing speed causes the generation of excessive heat input and flash formation in the weld (figure 10). In case (e), high advancing and rotating speeds lead to a more unified distribution of the material after weld. However, from figure 11e, it can be seen that the weld presents with a cavity type defect due to abnormal stirring. The position of this defect is different from that case (a) being closer to the tool pin. Case (f), due to a very low rotating speed, suffers from lack of material filling. A wormhole defect, attributed to insufficient local plastic flow, is obtained in this case and shown in figure 11f. When the rotating velocity is not sufficiently high, the plastic strain rate is not enough at the interface level. Therefore, the temperature generated by plastic dissipation and frictional heating are not sufficient to maintain the plastic flow. Due to the lack of plastic flow, the band structure is not fully constructed and there is lack of filling.

It is important to mention that each cut is made after the material tracers have completely passed through the stirring zone. This means that the position of these tracers does not change anymore in the vertical and transversal directions. These cuts show that the defects are completely developed in the advancing direction up to the limit of the tracer domain. For this reason, the observed defects are developed in the path. It is found that high welding velocities lead to the creation of voids underneath the top surface of the weld or on the advancing side at the border of the weld nugget. Further increase in the welding velocity prompts the development of larger wormhole defects, and this does not allow the band structures to get fully constructed. 
A cross-sectional view of XY plane for cases (e) and (f), they are added in figure 12. One can see that despite case (f), the band structures in case (e) are constructed.

Figure 13 illustrates the approximate process window corresponding to the defects appeared in this test using a featureless cylindrical pin. The borders of the sound joint area can be better identified if additional simulations with different welding parameters are performed.

If a finer division of the tracers in the transversal direction is chosen, the enhanced resolution allows the microstructural characteristics of the weld to be observed with a higher level of detail. The basal plane is the plane perpendicular to the principal axis in the crystal systems. The trace of the basal plane is an ellipsoid encircling the rotating pin surface. The schematic illustration of the trace of the basal plane is shown in figure 14 . The basal plane of the material is extruded amid every tool rotation. If a transversal cut perpendicular to the welding direction is made on the trace of the basal plane, the cross section depicts an elliptical stir zone and an onion ring structure (figure 15). The onion rings are a geometric effect created by the simple extrusion of the elliptically layered material flow at every tool revolution and the transversal cut on its cross section. The separating distance between the rings is generally equivalent to the advancing distance of the tool in one revolution. The semi-circular onion rings detected in the stir zone imply that the material flow is repeated in each rotation of the tool.

The two sets of particles placed along the vertical symmetry plane at the weld centre in the original position (figure 7) represent the oxide layer, in order to show the joint line remnant during the FSW processing. Figures 9 and 11 show that different process welding parameters lead to very different joint line remnants. The reversed C-shaped pattern of the joint line remnant in the stir zone can be seen in those cases where the rotating velocity is $600 \mathrm{rpm}$. The curvature of the C-shape is greater if the advancing velocity is higher. By decreasing the rotating velocity, the C-shaped curvature of the joint line remnant is diminished while by increasing to $1200 \mathrm{rpm}$ the joint line remnant changes the location and is positioned on the opposite side.

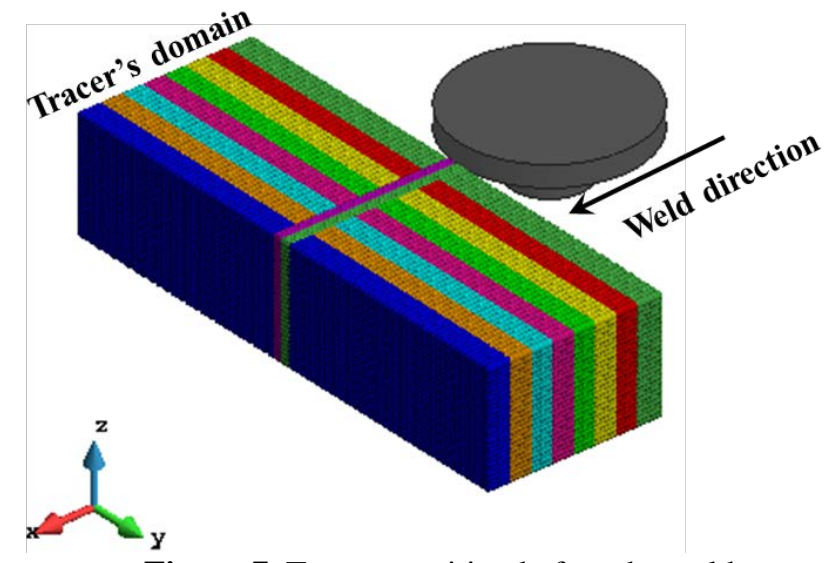

Figure 7. Tracers position before the weld 


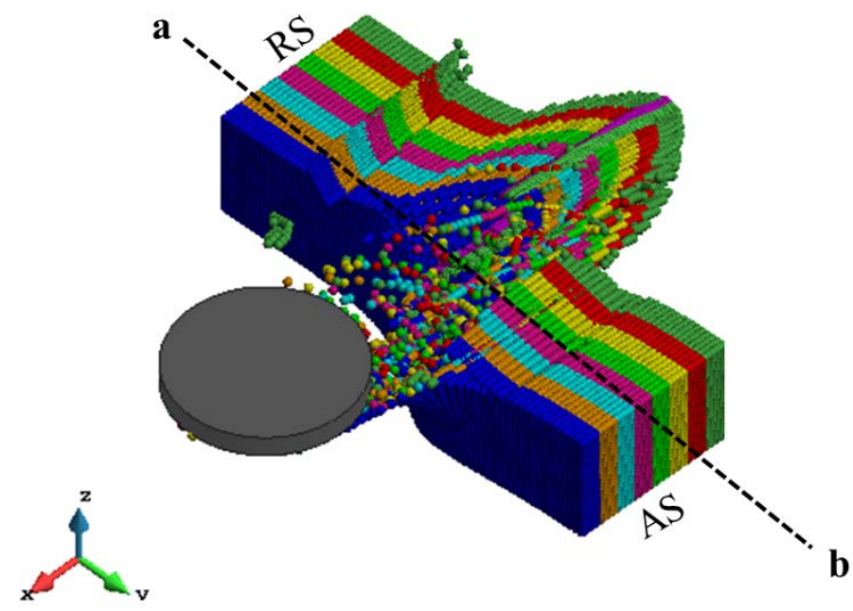

Figure 8. Tracers position after the weld (featureless cylindrical pin, case (a))

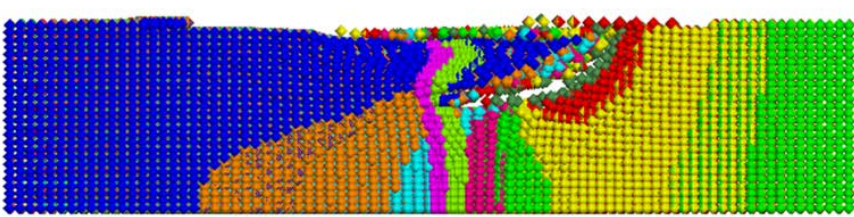

(a) $400 \mathrm{~mm} / \mathrm{min}$ $600 \mathrm{rpm}$

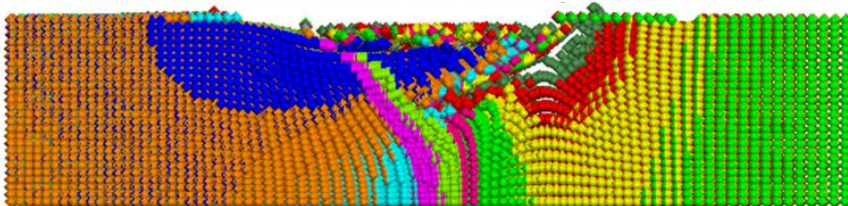

(b) $400 \mathrm{~mm} / \mathrm{min}$

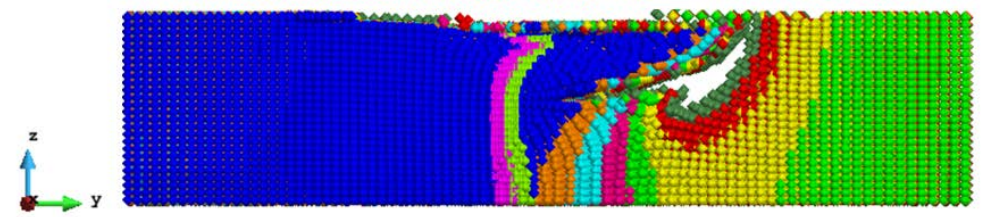

(c) $200 \mathrm{~mm} / \mathrm{min}$

Figure 9. Material pattern on a vertical plane and defect formation (featureless cylindrical pin, cases (a), (b) and (c))

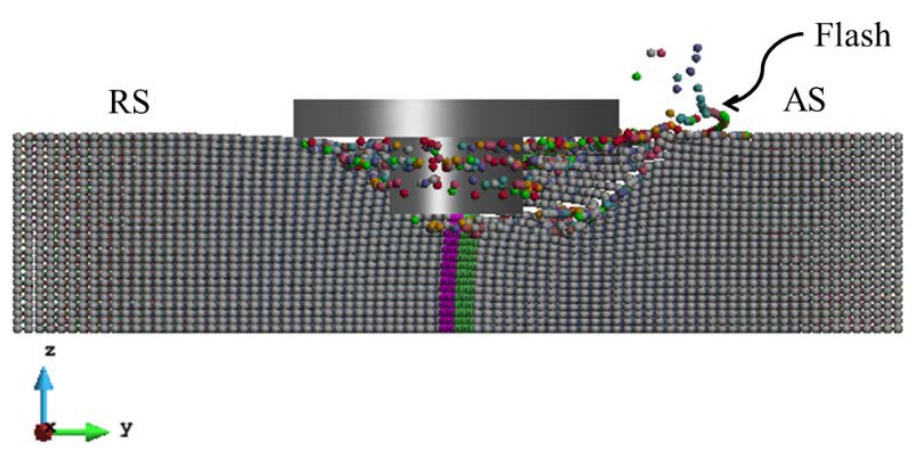

Figure 10. Flash formation with featureless cylindrical pin (case (d)) 


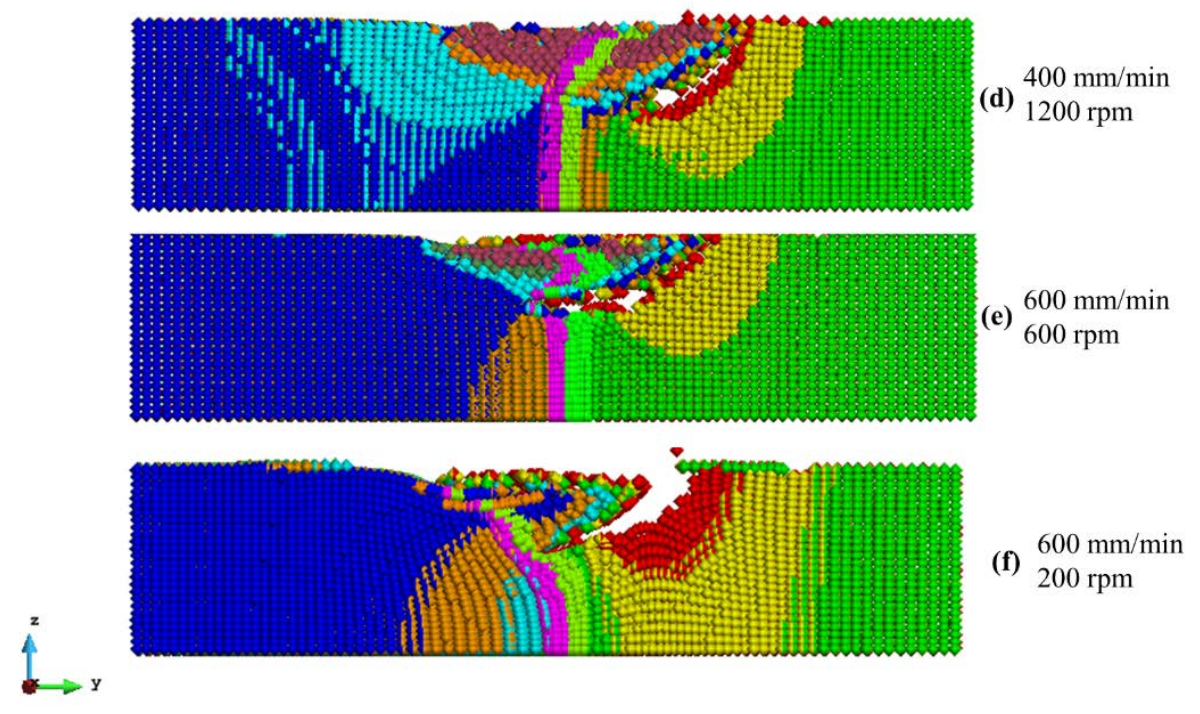

Figure 11. Material pattern on a vertical plane and defect formation (featureless cylindrical pin, cases (d), (e) and (f))

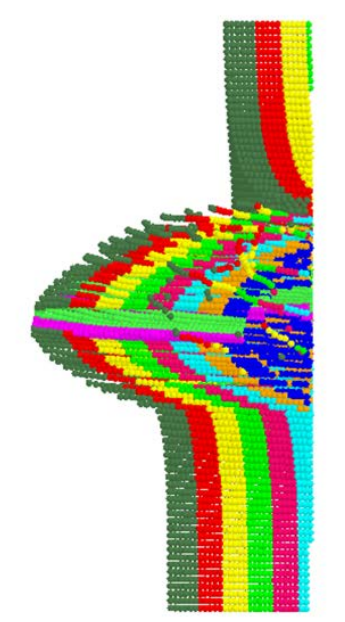

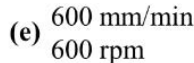

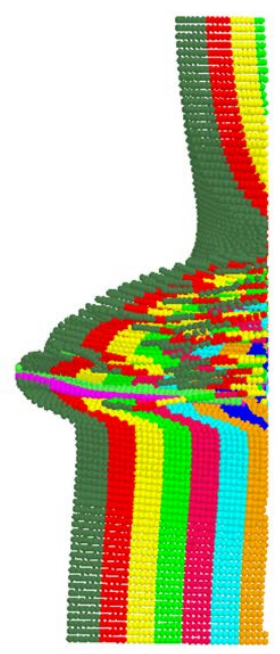

(f) $600 \mathrm{~mm} / \mathrm{min}$ $\underbrace{}_{x \rightarrow x} \quad$ (f) $200 \mathrm{rpm}$

Figure 12. Material pattern on a horizontal plane (featureless cylindrical pin, cases (e) and (f)) 


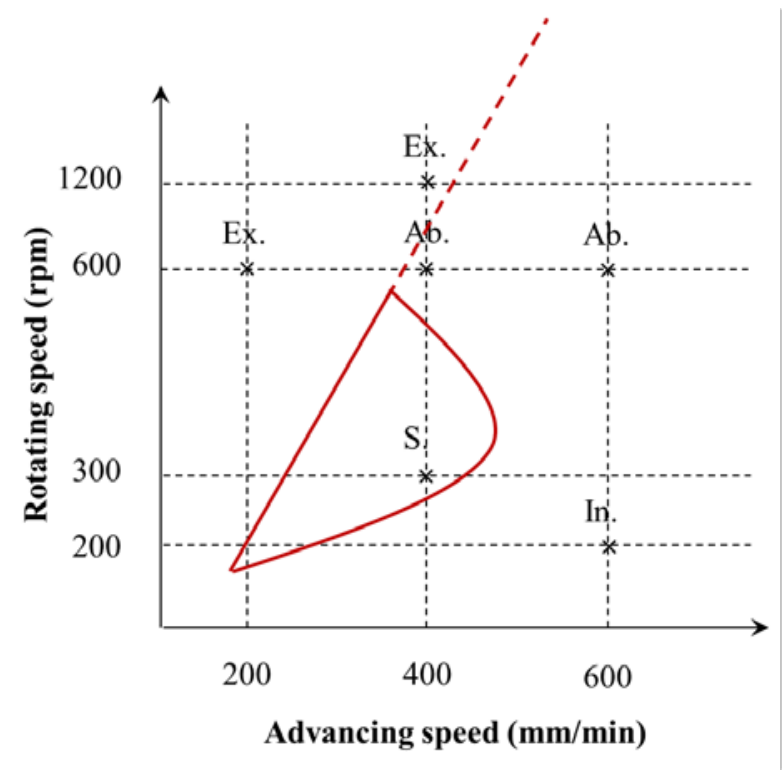

Figure 13. Approximate FSW process window and corresponding weld defects (featureless cylindrical pin)

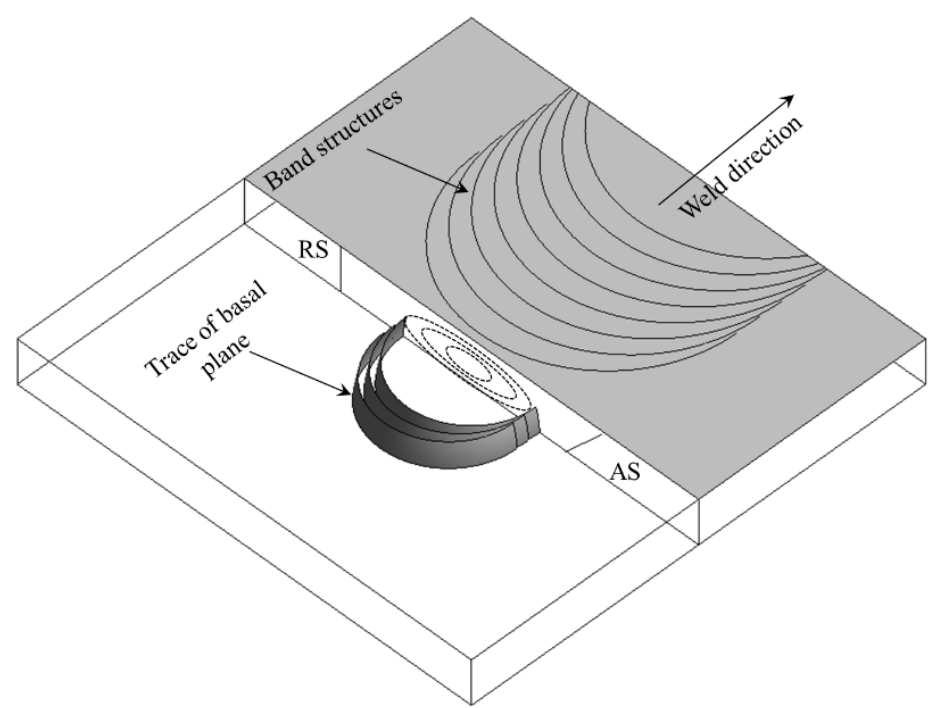

Figure 14. Schematic illustrations of the trace of the basal plane with onion rings on the transversal cross section 


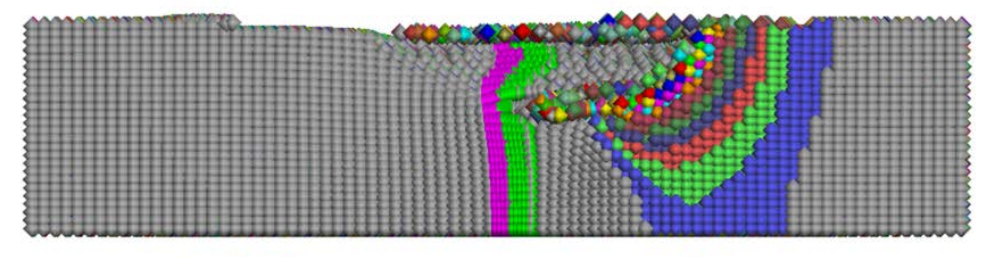

(a) $400 \mathrm{~mm} / \mathrm{min}$
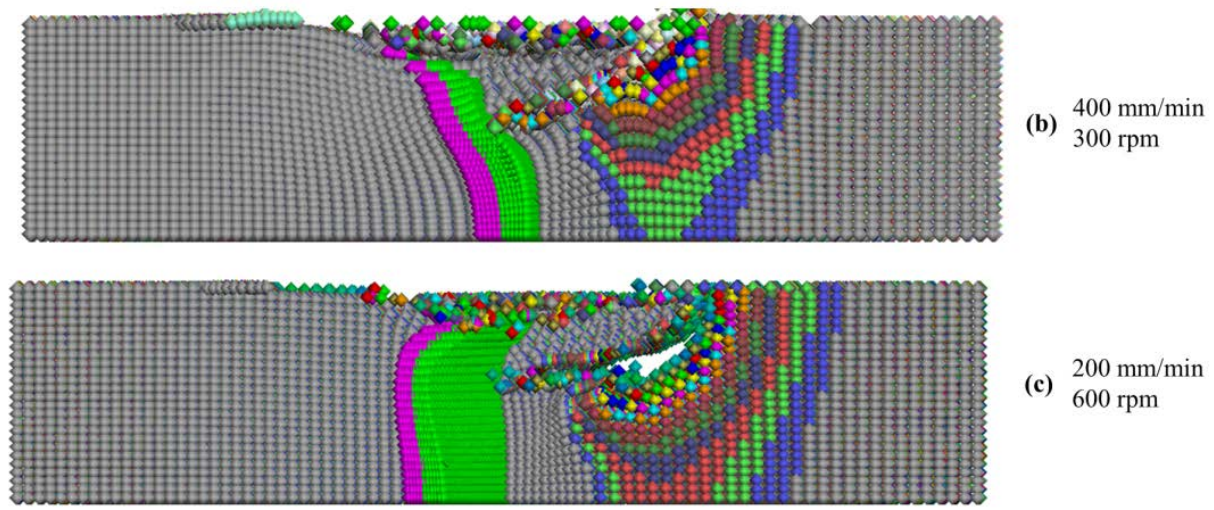

Figure 15. Onion rings in the weld zone (featureless cylindrical pin, cases (a), (b) and (c))

\subsection{THREADED CYLINDRICAL PIN}

In this section the numerical simulation of defect formation is studied with regard to different process parameters in FSW processes using a threaded cylindrical pin is performed.

A flat shouldered tool with $18 \mathrm{~mm}$ diameter with a threaded pin of $7 \mathrm{~mm}$ average diameter is considered. The height of the pin is $4 \mathrm{~mm}$ (figure 16). No tilt angle is used. The material used and the process parameters are identical to those of the featureless cylindrical pin. Like in the previous section, three cases of tool advancing and rotating speeds (clockwise) are considered; (a) $400 \mathrm{~mm} /$ minute and $600 \mathrm{rpm}$; (b) $400 \mathrm{~mm} /$ minute and $300 \mathrm{rpm}$; (c) $200 \mathrm{~mm} /$ minute and $600 \mathrm{rpm}$.

In case (a), the thermomechanical results obtained are validated against the experimental results and presented in [40].

In order to track the material flow and visualize the possible formed defects, a set of colour material tracers are placed in front of the tool similarly to the previous section. Once all the material tracers have passed through the tool, a planar cut perpendicular to the weld direction is made (figure 17).

The final pattern in the cutting plane is shown for all the three cases in figure 18 . Comparing figures 9 and 18, it can be seen that the threaded pin diminishes the amount of defects due to the higher stirring action. Features on the pin such as threads enhance the material flow for effective downward material movement and improve the material mixing. In cases (a) and (b) no defects are appreciated. Comparing to the similar cases for the featureless pin, a defect-free weld is achieved. Moreover, the defect size in case (c) is much reduced from the case (c) of section 3.1 where a featureless pin was used.

The threading effect also results in reducing size of the stir zone (figures 9 and 18) which is in accordance with the observation made by Threadgill et al. [43] revealing the impact of the tool pin profile on narrowing the stir zone.

Similarly, as in the previous section, three additional cases of welding parameters are studied: (d) $400 \mathrm{~mm} / \mathrm{minute}$ and $1200 \mathrm{rpm}$; (e) $600 \mathrm{~mm} /$ minute and $600 \mathrm{rpm}$; (f) 600 
$\mathrm{mm} / \mathrm{minute}$ and $200 \mathrm{rpm}$. Figure 19 shows the vertical observation plane on the final state of the material tracers for these cases. Defect-free welds are obtained in all the cases. It can be concluded that using the threaded pin shape the domain of sound joint illustrated in figure 1 is largely expanded due to the increase of the stirring action. Therefore, the defects produced by abnormal stirring are avoided.

Figure 20 illustrates the approximate process window corresponding to the defects appeared in this test using threaded cylindrical pin. Comparing with figure 13 where the featureless pin is used, the domain of the sound joint is very much enhanced.

Intersecting lines between the trace of the basal plane (cylindrical plane of the material during each rotation of the tool) and the cutting plane perpendicular to the weld direction depict the stir zone and the onion rings patterns (figure 21). This outcome was also observed by Park et al. [44]. The effect of the threads appears on the size of the elliptical onion rings patterns and stir zone. In case of the threaded tool pin, when the rotating velocity of the tool is higher (600 rpm), the onion rings are smaller than in case of the featureless tool pin (comparing figures 14 and 21). However, in case (b) with smaller rotating speed, the effect of the threads on the onion rings size is less noticeable.

Figures 18 and 19 demonstrate that different process welding parameters lead to very different joint line remnants. When the rotating speed is low (200 rpm and $300 \mathrm{rpm}$ in cases (b) and (f), respectively), the joint line remnant tends to the retreating side rather than the advancing side getting less affected by the rotation of the tool. The horizontal displacement of the joint line remnant from the weld line reduces by the distance from the top surface. This range of movement is greater in case of higher rotating velocities.

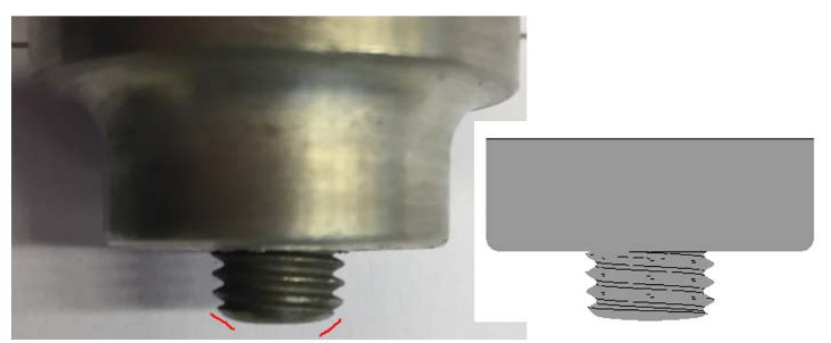

Figure 16. Threaded pin

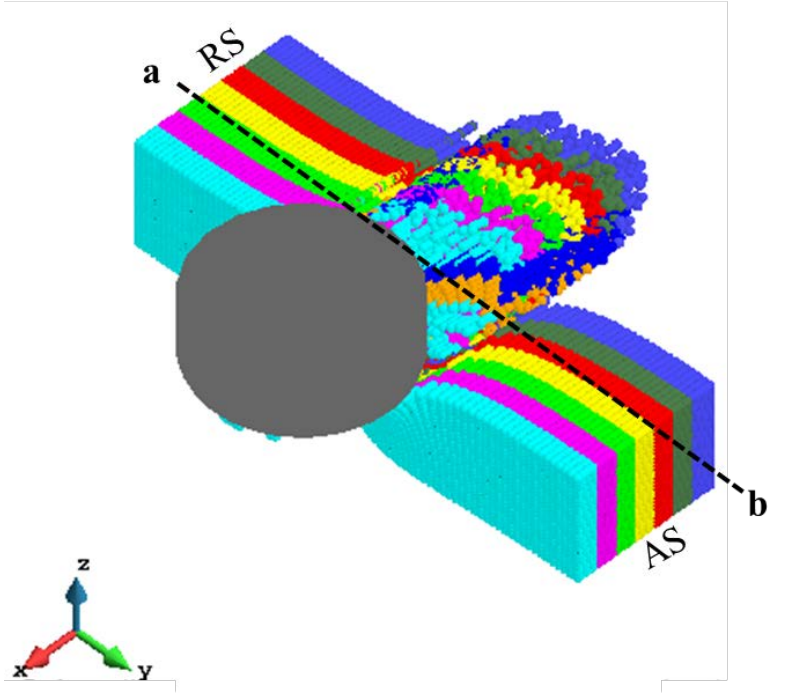

Figure 17. Tracers position after the weld (threaded cylindrical pin, case (a)) 

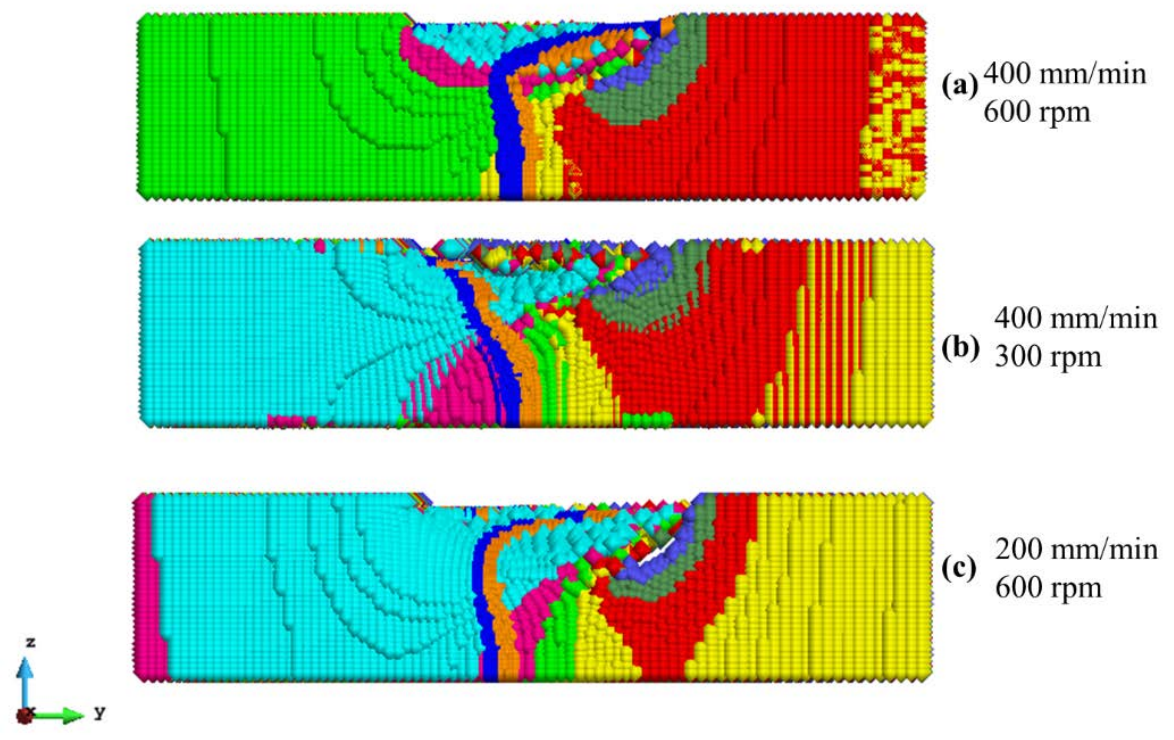

Figure 18. Material pattern on a vertical plane and defect formation (threaded cylindrical pin, cases (a), (b) and (c))

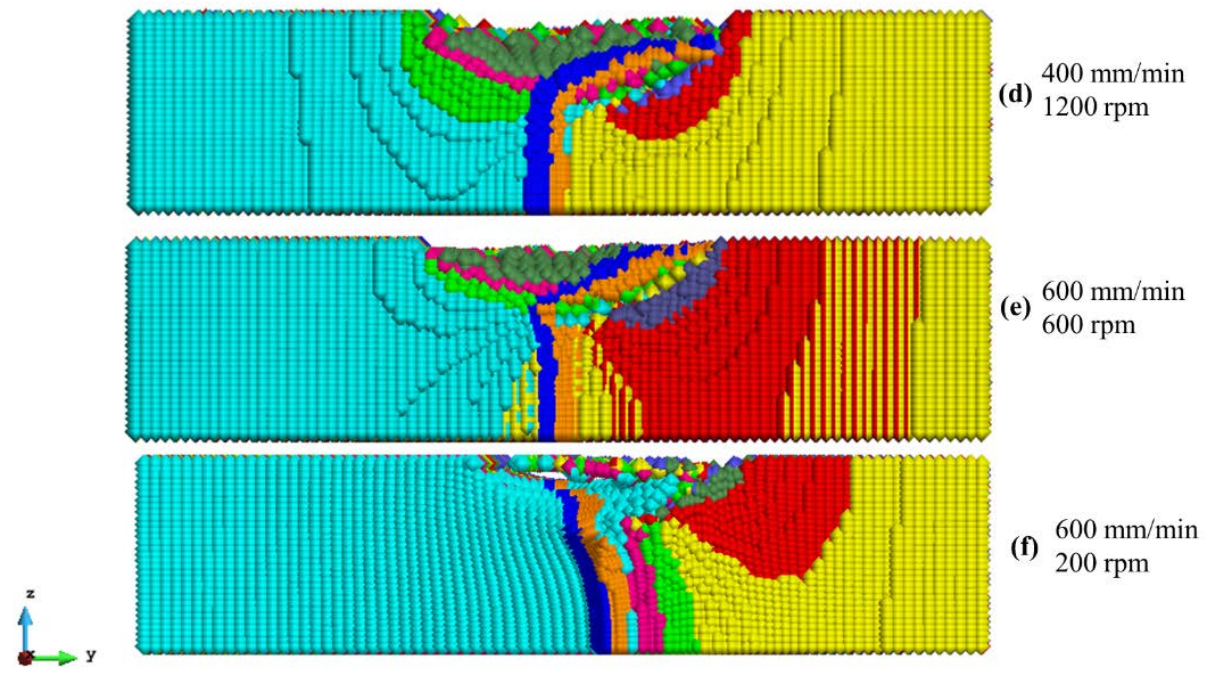

Figure 19. Material pattern on a vertical plane and defect formation (threaded cylindrical pin, cases (d), (e) and (f)) 


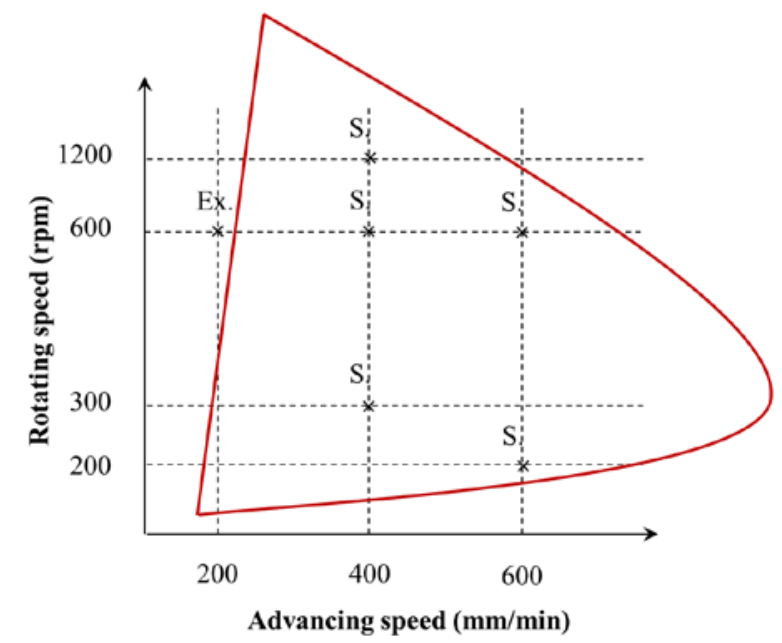

Figure 20. Approximate FSW process window and corresponding weld defects (threaded cylindrical pin)
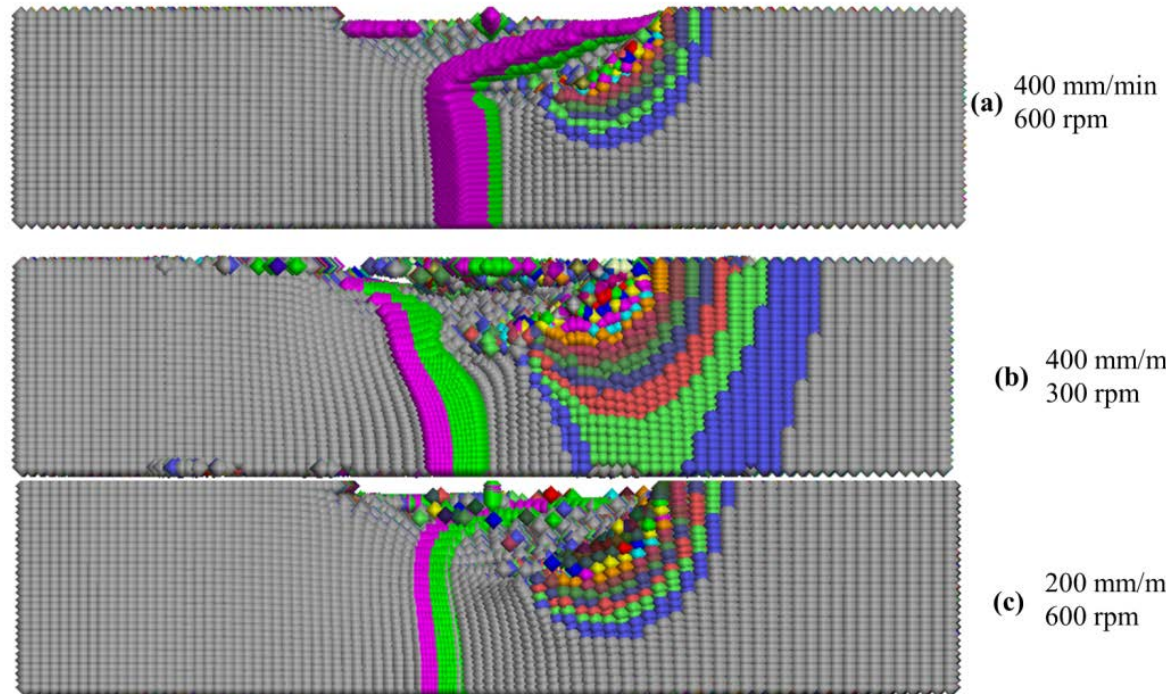

(b) $400 \mathrm{~mm} / \mathrm{min}$ $300 \mathrm{rpm}$

(c) $200 \mathrm{~mm} / \mathrm{min}$ $600 \mathrm{rpm}$

Figure 21. Onion rings in the weld zone (threaded cylindrical pin, cases (a), (b) and (c))

\section{SUMMARY AND CONCLUSIONS}

In this work, material flow and its effect on the formation of defects in FSW processes is simulated using a robust and accurate computational model. A wide range of defects such as voids, wormholes, joint line remnant and flash formation are accordingly predicted. The effect of the process parameters and the tool pin profile is also studied.

The study is performed using a material tracing technique within an apropos finite element-based framework for FSW modelling.

It is observed that the weld parameters strongly affect the defect formation. Defects can be generated due to abnormal stirring, insufficient or excessive heat input. Void and cavity formation due to the abnormal stirring occur when both rotating and advancing velocities are too high, which leads to the high gradient of the temperature between upper and lower parts and subsequent discontinuity in the material flow (cases (a) and (e)). 
Excessive heat generation due to the high rotating speed and low advancing speed softens the material of the workpiece to a high extent. It leads to the formation of a series of visible voids on the advancing side or flash formation (cases (c) and (d)). Insufficient heat input due to a very low rotating speed leads to improper mixing of the material, improper bonding and lack of filling and therefore formation of defects such as wormhole (case (d)).

Both the onion ring structures and the elliptical nugget shape of the stir zone are obtained in FSWelds together with the joint line remnant. In the threaded case, with lower advancing velocity the remnant line tends to move together with the rotating tool; in the featureless case, a reversed C-shaped pattern is observed except in the cases with low rotating speed.

The threaded effect results in increased stirring action and expanding the range of the welding parameters for a sound joint. 


\section{REFERENCES}

[1] Thomas W.M., Nicholas E.D., Needham J.C., Murch M.G., Temple-Smith P. and Dawes C.J. (1991) Friction-stir butt welding. GB Patent No. 9125978.8, International Patent No. PCT/GB92/02203.

[2] Zhang S., Shi Q., Liu Q., Xie R., Zhang G., Chen G. (2018) Effects of tool tilt angle on the in-process heat transfer and mass transfer during friction stir welding, International Journal of Heat and Mass Transfer 125, 32-42.

[3] Kim Y.G., Fujii H., Tsumura T., Komazaki T. and Nakata K. (2006) Effect of welding parameters on microstructure in the stir zone of FSW joints of aluminum die casting alloy, Mater. Lett. 60(29): 3830-3837.

[4] Ren S.R., Ma Z.Y. and Chen L.Q. (2007) Effect of welding parameters on tensile properties and fracture behavior of friction stir welded Al-Mg-Si alloy, Scripta Mater. 56(1): 69-72

[5] Chen G., Li H., Wang G., G. Zhiqiang, Z. Shuai, D. Qilei, W. Xibo, Z. Gong, S. Qingyu (2018) Effects of pin thread on the in-process material flow behavior during friction stir welding: a computational fluid dynamics study, Int. J. Mach. Tools Manuf. 124:12-21

[6] Su H., Wu C.S., Bachmann M. and Rethmeier M. (2015) Numerical modeling for the effect of pin profiles on thermal and material flow characteristics in friction stir welding, Mater. Des. 77: 114-125

[7] Yu Z., Zhang W., Choo H., Feng Z. (2012) Transient heat and material flow modeling of friction stir processing of magnesium alloy using threaded tool, Metall. Mater.Trans. A 43 (2): 724-737.

[8] Morisada Y., Imaizumi T. \& Fujii H. (2015) Clarification of material flow and defect formation during friction stir welding, Science and Technology of Welding and Joining 20 (2): 130-137.

[9] Didžiokas R., Januteniene J. \& Jonaityte J. (2008) The impact of the internal welding defects on the joint strength, Transport, 23:3, 240-244

[10] Podržaj P., Jerman B. \& Klobčar D. (2015) Welding defects at friction stir welding. Metalurgija. 54. 387-389.

[11] Rasti J. (2018) Study of the welding parameters effect on the tunnel void area during friction stir welding of 1060 aluminum alloy, The International Journal of Advanced Manufacturing Technology, 97 (5-8): 2221-2230

[12] Arbegast W.J., Coletta E.R., Li Z., (2001) Characterization of Friction Stir Weld Defect Types, 2001TMS Annual Spring Meeting, New Orleans, LA, February 11-15

[13] Zhou N., Song D., Qi W., Li X., Zou J., Attallah M. M. (2018) Influence of the kissing bond on the mechanical properties and fracture behaviour of AA5083-H112 friction stir welds, Materials Science and Engineering: A, 719: 12-20.

[14] Zhang H., Liu H. (2012) Characteristics and Formation Mechanisms of Welding Defects in Underwater Friction Stir Welded Aluminum Alloy, Metallography, Microstructure, and Analysis, 1(6): 269-281

[15] Reynolds A.P. (2000) Visualisation of material flow in autogenous friction stir welds Science and Technology of Welding and Joining, 5(2): 120-124.

[16] Hou X., Yang X., Cui L., Zhou G. (2014) Influence of joint geometry on defects and mechanical properties of friction stir welded AA6061-T4 T-joints, Materials and design 53:106-117

[17] Khan N. Z., Siddiquee A. N., Khan Z. A., Shihab S. K. (2015) Investigation on tunneling and Kissing bond defects in FSW joints for dissimilar aluminum alloys, Journal of alloys and Compounds 648:360-367. 
[18] Zhao Y., Zhou L., Wang Q., Yan K., Zou J. (2014) Defects and tensile properties of 6013 aluminum alloy T-joints by friction stir welding, Materials and Design 57:146155.

[19] Pandya Sh., Mishra R. S., Arora A. (2019) Channel formation during friction stir channeling process - A material flow study using X-Ray micro-computed tomography and optical microscopy, Journal of Manufacturing Processes 41: 48-55

[20] Zeng X. H., Xue P., Wang D., Ni D. R., Xiao B. L., Wang K. S. \& Ma Z. Y. (2018) Material flow and void defect formation in friction stir welding of aluminium alloys, Science and Technology of Welding and Joining, 23(8): 677-686.

[21] Zhao Y.H., Lin S.B., Wu L., Qu F.X. (2014) The influence of pin geometry on bonding and mechanical properties in friction stir weld $2014 \mathrm{Al}$ alloy, Mater Lett, 59 (23): 2948-2952.

[22] Reza-E-Rabby M., Tang W., Reynolds A.P. (2017) Effects of thread interruptions on tool pins in friction stir welding of AA6061, Sci Technol Weld Joining, 23 (2):114124.

[23] Zettler R., Lomolino S., Dos Santos J.F., Donath T., Beckmann F., Lippman T., Lohwasser, D. (2004) A study on material flow in FSW of AA 2024-T351 and AA 6056T4 alloys, 5th International FSW Symposium-Metz France

[24] Das B., Pal S. S., Bag S. (2016) Defect Detection in Friction Stir Welding Process Using Signal Information and Fractal Theory, Procedia Engineering 144:172-178

[25] Vilaça P. and Santos T. G. (2011) Non-Destructive Testing Techniques for Detecting Imperfections in Friction Stir Welds of Aluminium Alloys, Aluminium Alloys, Theory and Applications, Ch 5, InTech, DOI: 10.5772/14743 •

[26] Dialami N., Chiumenti M., Cervera M., Agelet de Saracibar (2017) Challenges in Thermo-mechanical Analysis of Friction Stir Welding Processes, Archives of Computational Methods in Engineering, 24 (1): 189-225.

[27] Y. Zhao, J. Han, Domblesky J. P., Yang Z., Li Z., Liu X. (2019) Investigation of void formation in friction stir welding of 7N01 aluminum alloy, Journal of Manufacturing Processes, 37: 139-149

[28] Al-Badour F., Merah N., Shuaib A., Bazoune A. (2013) Coupled Eulerian Lagrangian finite element modeling of friction stir welding processes, J Mater Process Technol 213(8):1433-1439

[29] Zhu Z., Wang M., Zhang H., Zhang X., Yu T. and Wu Z. (2017) A Finite Element Model to Simulate Defect Formation during Friction Stir Welding, Metals, 7(7), 256.

[30] Fraser K., St-Georges L. and Kiss L. I. (2016) A Mesh-Free Solid-Mechanics Approach for Simulating the Friction Stir-Welding Process, Joining Technologies SP Ch. 3, InTech publisher http://dx.doi.org/10.5772/64159

[31] Atharifar H, Lin DC, Kovacevic R; (2007) Studying tunnel-like defect in friction stir welding process using computational fluid dynamics: Mat. Sci. Tech., Detroit MI.

[32] Zhu Y., Chen G., Chen Q., Zhang G., Shi Q. (2016) Simulation of material plastic flow driven by non-uniform friction force during friction stir welding and related defect prediction, Materials and Design 108: 400-410.

[33] Tutunchilar S., Haghpanahi M., Besharati Givi M.K., Asadi P., Bahemmat P. (2012) Simulation of material flow in friction stir processing of a cast Al-Si alloy, Materials and Design 40: 415-426

[34] Dialami, N.; Cervera, M.; Chiumenti, M.; Segatori, A. (2019) Prediction of joint line remnant defect in friction stir welding, International Journal of Mechanical Sciences, 151: 61-69. 
[35] Dialami N., Chiumenti M., Cervera M., Agelet de Saracibar C. and Ponthot J.-P. (2013) Material Flow Visualization in Friction Stir Welding via Particle Tracing, International Journal of Metal Forming, 1-15.

[36] Dialami N., Chiumenti M., Cervera M., Agelet de Saracibar C. and Ponthot J.-P., (2014) Numerical simulation and visualization of material flow in friction stir welding via particle tracing, Numerical Simulations of Coupled Problems in Engineering,157-169, Springer International Publishing.

[37] Dialami, N., Chiumenti, M., Cervera, M. and Agelet de Saracibar, C. (2013) An apropos kinematic framework for the numerical modeling of friction stir welding. Computers and Structures 117:48-57.

[38] Dialami N., Cervera M., Chiumenti M. and Agelet de Saracibar C., (2017) A fast and accurate two-stage strategy to evaluate the effect of the pin tool profile on metal flow, torque and forces during friction stir welding, International Journal of Mechanical Sciences, 122, 215-227.

[39] Dialami N., Chiumenti M., Cervera M., Segatori A. and Osikowicz W., (2017) Enhanced friction model for Friction Stir Welding (FSW) analysis: simulation and experimental validation, International Journal of Mechanical Sciences, 133: 55-567.

[40] Dialami, N.; Cervera, M.; Chiumenti, M.; Segatori, A.; Osikowicz, W. (2017) Experimental validation of a FSW model with an enhanced friction model: Application to a threaded cylindrical pin tool. Metals 7: 491.

[41] Dialami N., Cervera M., Chiumenti M. (2019) Effect of the Tool Tilt Angle on the Heat Generation and the Material Flow in Friction Stir Welding, Metals, 9(1): 28.

[42] Dialami N, Cervera M, Chiumenti M. (2018) Numerical modelling of microstructure evolution in friction stir welding (FSW), Metals 8(3):183.

[43] Threadgill P., Leonard A., Shercliff H., and Withers P. (2009) Friction stir welding of aluminium alloys, International Materials Reviews 54(2): 49-93.

[44] Park, S.H.C., Sato, Y.S. \& Kokawa, H. (2003) Basal plane texture and flow pattern in friction stir weld of a magnesium alloy, Metall and Mat Trans A 34(4): 987994. 